\title{
Working for a Scientific Society
}

\author{
Martin Frank \\ American Physiological Society, Bethesda, Maryland 20814 \\ Correspondence: mfrank@the-aps.org
}

Opportunities for employment of PhD scientists exist within the world of scientific societies. Societies exist to serve the needs of their scientific or engineering constituencies. As membership organizations, they provide their constituents with access to meetings, publications (both books and journals), educational programs, and advocacy assistance. Within many of these societies, leadership positions and associated coordinator/analyst positions can be filled by someone with a PhD. Examples of positions in societies include science policy/ government relations, education, publications, communications, and executive departments. Interested PhDs should demonstrate their interest by volunteering to participate in society outreach or committee activities. The critical element is to remember that as a $\mathrm{PhD}$ you have the critical thinking and problem-solving ability to succeed in whatever career you pursue. The key is to demonstrate that these abilities are applicable to the available positions in the association.

$\mathrm{N}^{\mathrm{a}}$ ational scientific and engineering societies exist to fulfill a scientific or engineering purpose or to serve the needs of a scientific or engineering audience. Typically, they have a nonprofit status and at least 100 members and do one or more of the following: (1) publish a peer-reviewed journal; (2) hold regularly scheduled professional or technical meetings; (3) produce standards; and (4) offer continuing education.

The Council of Engineering and Scientific Society Executives (CESSE) represents a small subset of the association world that is more broadly represented by the American Society of Association Executives (ASAE), a society representing more than 10,000 societies. This chapter is based on the author's experience at the American Physiological Society (APS), but in order to confirm that other societies provide similar opportunities for $\mathrm{PhD}$ scientists, a survey was conducted among members of CESSE. There are $\sim 200$ CESSE member societies and responses were received from 36 of these societies. The responding societies employ 1288 individuals, 75 of whom possess PhDs.

Job opportunities for $\mathrm{PhDs}$ in scientific societies span a wide range of positions within a multitude of departments. For example, positions exist in the following departments/areas: education, publications, communications, government relations/science policy, and executive administration. As an example of a society structure, Figure 1 shows the organizational chart for the APS.

The history of the APS (see Box 3, page 9) is typical of the course taken by many associations as they progressed from organizations led and managed by volunteer leadership to organizations managed by professional staff. In many cases, the individual hired to lead the

Editors: Kaaren Janssen and Richard Sever

Additional Perspectives on Career Options for Biomedical Scientists available at www.cshperspectives.org

Copyright (C) 2018 Cold Spring Harbor Laboratory Press; all rights reserved; doi: 10.1101/cshperspect.a032888

Cite this article as Cold Spring Harb Perspect Biol 2018;10:a032888 
M. Frank
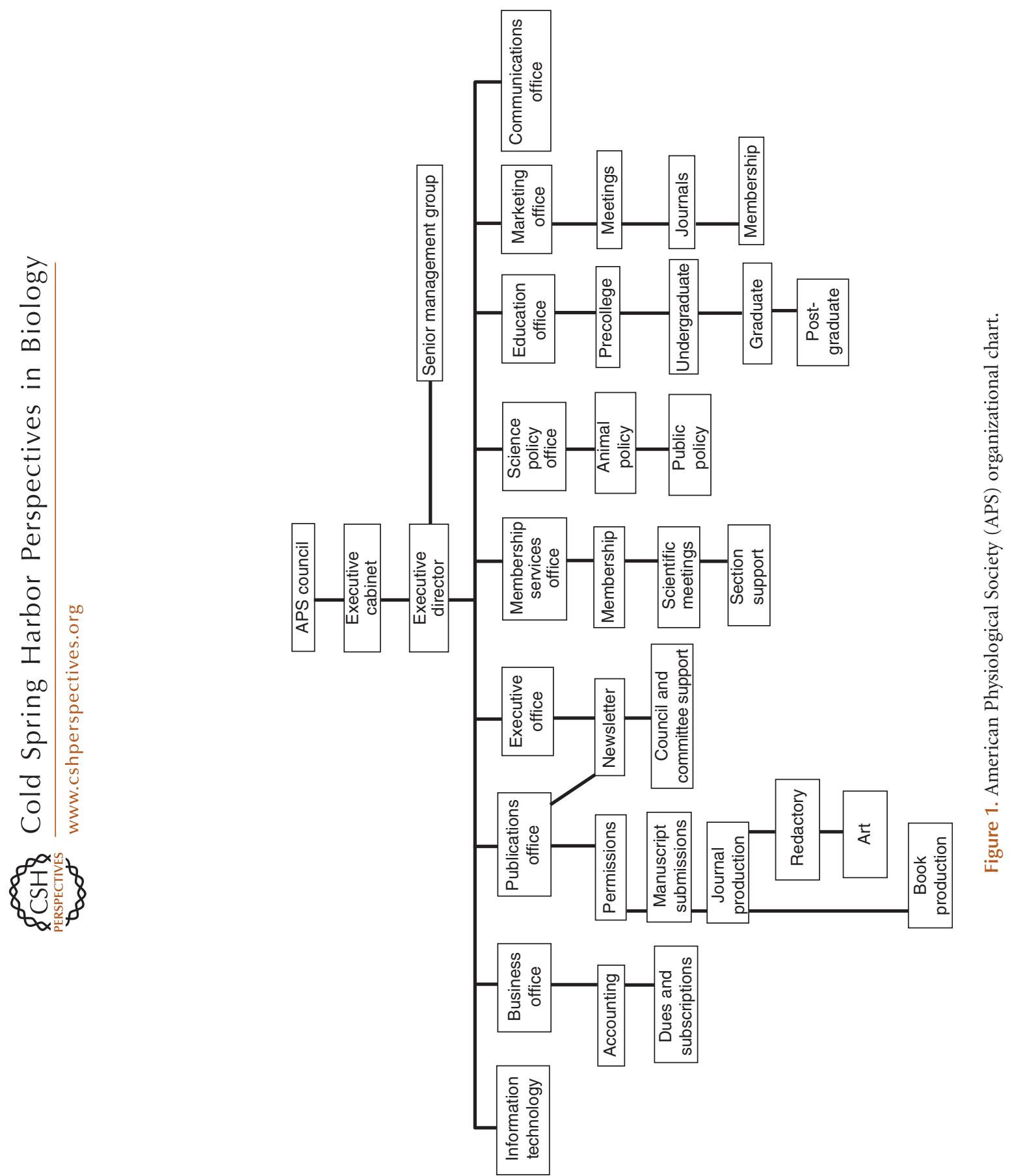
society has a doctorate in the relevant academic discipline, whereas in other cases, the leader has a business or management degree. Since its founding, the APS has grown to approximately 11,000 members and at the same time the society's staff has grown to 70 individuals. Of those, seven APS employees have $\mathrm{PhD}$ degrees - two in the humanities and the others in scientific fields. The five $\mathrm{PhD}$ scientists are employed as follows: executive director; director of education programs; education project coordinator; publications ethics manager; and science policy analyst. The two humanities PhDs are journal supervisors. This chapter describes the opportunities available to $\mathrm{PhD}$ scientists within the association world and provides guidance for professional scientists interested in obtaining these positions.

\section{JOBS}

The CESSE survey revealed the primary areas in which $\mathrm{PhDs}$ are employed, including science policy/government relations, communications, education, publications, and executive positions. Below is an overview of some of the duties individuals in these positions exercise as they strive to advance the mission of the association.

\section{Science Policy and Government Relations}

In reviewing the job titles associated with this area, one might find science policy analyst, science policy or government relations director, or legislative officer. In general, the responsibilities for all are the same and the distinguishing characteristics are the level of authority and responsibility. It is obvious that a director level position will have supervisory responsibility and provide leadership and direction for the society's overall science policy efforts.

Science policy/government relations specialists work with the society's leadership to develop the policy positions taken by the organization. Issues of interest to the organization might relate to research funding; the conduct, regulation, or management of government-funded research; or regulatory oversight. In most associations, the policy response is developed in conjunction with committees of volunteers. For the APS, two committees oversee the development of policy for the society: the Science Policy Committee and the Animal Care and Experimentation Committee. In addition, the APS, as with most societies, works in coalition with like-minded organizations in order to amplify position statements developed individually or jointly.

Science policy staff formulate policy and develop and compose documents that convey the society's policy positions, including position statements or white papers on the issue. They communicate outward to the officials responsible for policy implementation and to the membership so that they amplify the message and become an effective advocate for the policy. The policy analyst prepares letters to be sent to elected officials, congressional testimony to be presented by the society's leadership, and materials designed to encourage the membership to engage with their elected representatives so that they embrace the society's recommendations.

\section{Communications}

Increasingly, associations are recognizing the importance of communicating information about their organization's activities to their membership as well as to the public. The latter is especially important for associations that work in areas of interest to the public and contribute to the public debate on issues. The positions available to $\mathrm{PhD}$ scientists in communications departments are often related to their ability to translate the scientific topic area into something that can be understood by the lay public. Positions available include communications specialist and director and social media manager. Although communications involves issuing press releases announcing awards to members, election of officers, publication of a study, or presentation of research at a meeting, it increasingly involves posting of such information to Facebook, Twitter, or LinkedIn. The communications staff must be familiar with social media and the means to speed information out to their communities. In addition, associations are increasingly hiring individuals to 
M. Frank

promote their mission and activities through blogging, either on a full- or part-time basis.

At the APS, the director of communications is responsible for developing and implementing a strategic plan for communicating the benefits of, and appreciation for, the science of physiology, as well as the APS itself and its programs. This includes but is not limited to press releases for journal articles, presentations at the society's meetings, development of a consumer website, and social media outreach. The communications director and communications specialists may be $\mathrm{PhD}$ scientists but it is critical that the individuals within the department have excellent writing and verbal skills. In many ways, the communications issued by the department become the "face" of the organization. Individuals within the communications department must be able to work closely with members of their committee but also interact with other departments within the society to decide on the information to promote and programs to feature in press releases and social media. The communications staff is also responsible for responding to media inquiries and identifying the individuals most capable of talking with the media.

\section{Education}

Education activities in most associations cover a broad expanse of activities. These might include the management of scientific meetings but most relate to management of programs focusing on $\mathrm{K}-12$ through professional education. Overseeing the former, a scientist with a $\mathrm{PhD}$ may serve as a meeting planner and a grant writer. For those employed in an education department, the mission might relate to development of K-12 programs, undergraduate or graduate programs, or postdoctoral certification programs. Education activities might focus on increasing diversity within the discipline, increasing the representation of women, enhancing opportunities for trainees, or providing information about career opportunities. The professional education staff is responsible for implementing the society's education programs; overseeing externally funded education projects, including development of project products; evaluation of projects; and dissemination of final project reports in the literature. They are also responsible for overseeing internally funded education activities and award programs. The positions within such a department include education project coordinator, education or professional development specialist, or education director. In all positions, knowledge of the program and ability to write clearly are necessary. These qualifications provide opportunities for the individual to become responsible for writing proposals to federal agencies and foundations to support the society's activities and preparing annual reports on the programs for the membership and leadership.

\section{Executive Office}

PhDs often find opportunities within the executive offices of scientific societies. These jobs might be the association's executive director or deputy executive director, foundation director, or development officer. The role of the foundation director or development officer involves raising funds to advance and implement society programs. The scientific experience and expertise of the incumbent allows them to talk science with the individuals with whom they meet to raise funds. The positions require unique skills that allow the incumbent to visit with individuals and groups to solicit support by making oral presentations and submitting written proposals. In some cases, the development officer's position can be filled by an individual early in their professional career who possesses the oral and written skills as well as the personality needed to solicit program support for the association.

In general, the executive director (chief executive officer, or CEO) position is filled by a more senior individual who has had prior experiences that have demonstrated his or her management and communications skills. However, in many larger organizations, there are opportunities for a more junior $\mathrm{PhD}$ to become a deputy executive director with the potential for promotion to a CEO position. The executive director generally reports directly to the volunteer leadership (board or council) and is responsible for carrying out the society's functions and 
managing the operation. The deputy executive director reports to the $\mathrm{CEO}$ and is responsible for overseeing and managing a subset of the executive director's responsibilities.

The CEO serves as principal administrative officer of the society, responsible for the management of the central office and the conduct of day-to-day operations. He or she is responsible for selecting, evaluating, and promoting all personnel and coordinating these activities with the association's department heads. The CEO provides overall supervision of the department directors and all other senior managers. Working closely with the finance director to develop the annual budget, the CEO receives and distributes copies of financial reports from investment counselors managing the association's reserve funds and has discretionary and signing powers for the society's investment funds. As a PhD scientist, the CEO often speaks on behalf of the association, especially when the society's president is unavailable.

\section{Publications}

Most scientists with $\mathrm{PhDs}$ are knowledgeable about publications and, depending on how well versed they are in writing and editing, it is possible to develop this experience into a career in publications. A number of job opportunities are open to $\mathrm{PhDs}$ in this arena. These range from copy editor to positions as journal supervisors, managing editors, publication ethics officers, art editors, news staff writer, scientific editor, or publications director.

Most societies issue a newsletter on a regular basis to inform the membership of activities occurring within the organization. In some cases, as with $A S B M B$ Today, the newsletter of the American Society for Biochemistry and Molecular Biology, the content includes summaries of recent papers published in their research journals and profiles of ASBMB member scientists. The preparation of these articles falls to scientific staff writers who translate the science into more readily accessible prose.

PhDs can also be hired as scientific journal editors when the journal is managed within the society. The scientific editor recruits associate editors and editorial board members, assigns manuscripts for review, and determines which articles will be published in the journal. For most societies, the scientific editor resides in an academic institution, but there are some instances where the scientific editor is a fulltime employee of the association. A more likely scenario is for the $\mathrm{PhD}$ to work as a managing editor for the journal, interacting closely with the scientific editor to oversee the review, copyediting, and publication of manuscripts.

The APS recently hired a $\mathrm{PhD}$ scientist to serve as the publication ethics officer. With 14 scientific journals, we have seen an increasing number of ethical violations. It is the responsibility of the ethics officer to work with the art editors to determine whether figures have been manipulated, with copy editors and editors to determine whether text has been plagiarized, and to work with the publications committee to determine whether actions must be taken to punish the offender.

Although likely perceived as being overqualified, $\mathrm{PhDs}$ can be hired as copy editors, providing they have good writing and grammar skills. It is their responsibility to edit the accepted manuscripts to make them consistent with journal style.

In some cases, publication directors for scientific societies have a PhD. However, in all cases, they have extensive experience in publishing, including the business experience to develop budgets and negotiate contracts. The director prepares financial statements and budgets with input from the finance director and executive director, presenting the statements and budgets to the publications and finance committees for their approval. The director is also responsible for managing the publications staff, who, in the case of the APS, includes peer review staff, copy editors, art editors, and online editors.

\section{SKILLS AND QUALIFICATIONS}

You have completed your $\mathrm{PhD}$ degree, worked as a postdoctoral fellow, and possibly accepted your first position as an assistant professor. All of a sudden, you realize that you have had enough of the academic rat race and you want 
M. Frank

to try something else. What skills will you need to garner a job in the world of scientific societies? Believe it or not, the skills needed are essentially the same wherever you go with your PhD degree: people skills, problem solving, and management skills. What most $\mathrm{PhDs}$ fail to recognize is that although they might not have taken courses in management or communications, they are continually honing those skills while exercising their professional skills. PhD scientists manage students, technicians, and postdoctoral fellows working in their laboratories. They are responsible for developing budgets that are submitted as part of the proposal writing efforts associated with research funding, and if they are fortunate enough to get a research grant, they are responsible for managing resources to fulfill the goals of the project. Their success as scientists requires them to have outstanding oral and written skills in order to communicate the results of their science and to convince others of the relevance of the results. All of these experiences and skills will serve you well should you choose to look toward a position in a scientific society.

\section{GETTING A FOOT IN THE DOOR}

The challenge faced by each of us is how to get a "foot in the door" of a scientific society. The key is to join a society, to participate in its programs and activities, and learn as much as possible about how the organization runs. In some cases, students and early-career PhDs are able to volunteer to serve on committees that will provide some insights into the society and its programs. These experiences can serve you well when you begin considering how best to use your PhD degree.

For those interested in science policy/government relations, start by attending sessions at meetings that provide guidance on how to become a science advocate. When asked to write in support of a piece of legislation, do so and inform the society's director of science policy of the response that you received from the legislator or executive branch correspondent. Reinforce your letter by calling the local office of your elected representative and visit the office to talk with staff responsible for the management of science issues. Volunteer to serve on the science policy committee to demonstrate your interest to the association's leadership. In some associations, there are opportunities for summer or one-year internships or fellowships designed to bring PhDs into the headquarters to learn more about advocacy. In addition, the American Association for the Advancement of Science (AAAS) offers Science and Technology Fellowships (http://fellowships.aaas.org), and the National Academies offer the Christine Mirzayan Science \& Technology Policy Graduate Fellowships (http://sites.nationalacademies .org/PGA/policyfellows/index.htm). Both programs are designed to help $\mathrm{PhD}$ scientists develop basic skills essential to working or participating in science policy at the federal, state, or local levels. Both of these programs will provide you with the skills needed to work within a scientific society.

If you are interested in communications, get involved with your association and its communications committee. PhDs can develop their communications and writing skills by contacting the press office at their academic institution. Often, the press office will welcome assistance in writing press releases promoting the scientific discoveries of the institution. In a sense, these should be considered internship opportunities because they will likely not involve remuneration or be a full-time position. It represents an opportunity for you to hone your writing skills. Similarly, explore the possibility of writing about the scientific discoveries at your institution for the college or local newspaper. For many young scientists already familiar with social media, demonstrated expertise will serve them well as associations seek out individuals who can strengthen the organization's social media presence. Develop a blog that discusses science and shares it in ways that can be understood by the public. The AAAS Mass Media Science and Engineering Fellows Program (http://www.aaas.org/programs/education/ MassMedia) provides another route for interested PhDs to develop the skills that can lead to a position in an association. The program provides participants with the tools and know-how 
Working for a Scientific Society

to accomplish the goal of translating science for the public.

Your desire to pursue a $\mathrm{PhD}$ marks you as an individual interested in education and discovery. Use that interest to get involved in the education programs of your society. Many associations have outreach programs that take PhDs into $\mathrm{K}-12$ classrooms to talk about science and the joys of discovery. Become engaged with the program or volunteer to work with the society's leadership to launch such an effort. The APS program is called PhUn (Physiology Understanding) Week (http://www.the-aps .org/mm/Education/K-12/EducationProjects/ PhUn-Week) and the Society for Neuroscience program is called Brain Awareness Week (http ://www.sfn.org/index.aspx?pagename=baw_ home). Volunteer for service on committees within the organization that focus on careers, diversity, and $\mathrm{K}$-professional education. Serve as a judge for undergraduate poster presentations at the annual meeting or volunteer to provide assistance at a local science fair. The key is to demonstrate interest in a career focusing on the educational mission of the association.

Publications are an area in which most $\mathrm{PhD}$ scientists have some expertise, based naturally on their experiences writing theses, papers, and abstracts. However, those experiences are only a subset of the publishing world. The entry level is usually as a copy editor for those with excellent grammar skills. New PhDs can be hired into associations with a book program as an acquisition editor, soliciting submission of book proposals from accomplished scientists. You can also seek an internship in a publishing organization, such as a university press, to gain expertise in journal or book publishing (see also Chapter 3), an important revenue source for a society.

Developing the management and business skills associated with running a society is probably the best way to get started in the executive office of an association. Make sure that you chronicle the skills that you are developing throughout your career so that when a management position becomes available, you can provide information on how you would, for example, handle a personnel issue, management problem, or budget deficit.

\section{CAREER PROGRESSION}

As you move into the world of scientific societies, it is important to recognize that there is a need to commit three-five years to any position taken in an association. A three-five-year commitment allows you to master the intricacies of your position, observe what others do in higher positions, and identify the skills needed for you to take more responsible positions. Then, as opportunities present themselves within your current association or others, you will be prepared to move ahead.

As described earlier, entry-level jobs are usually science policy analyst, communications specialist, education program coordinator, copy editor or acquisitions editor, or development specialist. These jobs provide a skill set that allows for advancement and contributes to future successes.

You can then use that experience to rise to managerial and director positions to guide the society's science policy, communications, and education or publications program. As you gain expertise and the confidence of the volunteer leadership, you may be tapped to become the deputy executive director or ultimately the executive director of the association. Clearly, attaining a leadership position in an organization generally requires that someone with a $\mathrm{PhD}$ has been in a management position for 10-15 years. This chapter deals primarily with association experience; however, the leadership skills required for selection as an executive director of a society can also be developed in positions in academia or government.

\section{WAY OUT}

Having spent 28 years as the executive director of the APS, I initially wondered why there is a need for a section titled "Way Out." However, I then realized that most executive directors do not have the benefit of such long tenure in their position. Indeed, most people in the world of scientific societies are much more mobile than I.

Once one has spent the requisite three-five years in a position, it is worth considering 
M. Frank

one's future options. If the position still provides challenges and opportunities to grow programs and activities, there is every reason for you to remain in your current position, especially if it is at a managerial or directorship level. However, if the activities associated with the position have become repetitive and there is no opportunity for growth and expansion, it is time to begin looking for other opportunities. In some cases, the opportunity might reside within your current association, especially if it is large enough to have a diversity of positions. Alternatively, it may be time to shop your expertise to another association, for example one with more opportunity for growth and creativity. Such positions are advertised on job boards provided by the ASAE and the CESSE. Choose wisely by learning as much as possible about the society and its programs. Ask questions of those currently working there to determine what the work environment is like, something you did when you decided to take a postdoctoral position. Most importantly, check out the finances to ensure that the association will be around long enough for you to make a difference.

\section{BOX 1. My Experience}

Thanks to a scholarship program for caddies in financial need from the Western Golf Association, I attended the University of Illinois-Urbana-Champaign, where I majored in physiology as a result of a class taught by Dr. F.R. Steggerda. After receiving my BS degree, I remained there for my PhD degree in physiology. To strengthen my research credentials, I held two postdoctoral positions-first at the Michigan Cancer Foundation, Detroit and then at Michigan State University in East Lansing-before accepting a position as an assistant professor in the department of physiology at George Washington University Medical School.

Being in Washington, D.C., I became interested in science policy and government support of research. Looking for a more policy-oriented career, I accepted a position at the National Institutes of Health (NIH) as executive secretary, Physiology Study Section, Division of Research Grants. As executive secretary, I was responsible for managing three review meetings per year, at which $\sim 100$ proposals were considered by members of the study section. However, I was not satisfied as the executive secretary of a study section and I was able to convince my bosses to allow me to work one day each week in the offices of senior NIH leadership. As a result, I was able to successfully compete for entrance into the Department of Health and Human Services Senior Executive Service Candidate Development Program in 1983. My first three-month assignment was in the Office of Program Planning and Evaluation, Office of the Assistant Secretary of Health, where I worked on orphan drug legislation.

While on assignment, I saw my current job advertised in Science. I interviewed during the summer of 1984 and started as the society's executive director in July 1985. I am now responsible for managing all aspects of the society's affairs, working cooperatively and collegially with the society's leadership and members, and directing a staff of approximately 70 individuals. During my tenure, the society has grown from an organization of 6000 members in 1985 to one of more than 11,000 members. Our annual budget has now grown to $\sim \$ 18$ million. I work with staff and volunteer leadership to ensure that the 14 journals published by APS have the best articles and come out on time and that the APS meetings show the best research in physiology and allow scientists to exchange ideas freely. Another goal is to ensure that the members and the general public learn about careers in physiology, the best ways to teach physiology, and new research going on in the field. We also deal with the government to make sure that there is enough money for members to do the research that is needed to move physiology forward. I have been fortunate to have been able to hire an outstanding staff and to have an excellent working relationship with the society's leadership. Working together, we have been able to advance the discipline and strengthen the APS. 
Working for a Scientific Society

\section{BOX 2. Ten Dos and Don'ts}

1. Do not be afraid to take an internship in an association to gain expertise.

2. Do chronicle the skills that you have developed during the course of your doctoral training and postdoctoral experience.

3. Do not forget to review your introductory letter to ensure that it highlights your interest in the position that is actually being advertised.

4. Do consider applying for one of the fellowship programs offered by the AAAS or other societies.

5. Do not ignore opportunities to volunteer for programs sponsored by your association in your areas of interest.

6. Do discuss your interest in a nonacademic research or teaching career with your mentors so they can help you to develop the necessary expertise.

7. Do not ignore opportunities to develop your expertise by working in your academic institution.

8. Do remember that your PhD has provided you with critical thinking skills and problem-solving abilities that are applicable to a career in a scientific society.

9. Do not think that your PhD provides you with all the skills that you need to succeed; take a business or communications course to hone your skills.

10. Do contact the leadership of your association to discuss your career interests and to gain knowledge about positions and opportunities in scientific societies.

\section{BOX 3. A Brief History of the APS ${ }^{1}$}

More than 125 years ago, the APS held its organizational meeting at Columbia University College of Physicians and Surgeons. The specific event that triggered its formation was the founding of the Congress of American Physicians and Surgeons, a federation of medical specialty societies that was conceived in 1886 with an emphasis on medical research rather than on medical practice. Participant societies were responsible for developing their own programs for the congress, and this provided the impetus for the development of the APS.

During the society's early years, its activities were managed by members serving in a voluntary manner. Indeed, the American Journal of Physiology, founded in 1898, the official journal of the APS, was initially managed and edited almost entirely by William Townsend Porter. It was not until the APS was 50 years of age that the burden of running it became too great on the volunteer elected leadership. Management by the volunteer leadership continued, however, throughout World War II and until 1947, when the Society hired Dr. Milton Lee, a physiologist, to serve as secretary-treasurer.

Lee hired staff to handle many of the administrative duties, eliminating the need for the volunteer offices of secretary and treasurer, and obtained its first permanent home in the offices of the National Academy of Sciences. Since the appointment of Lee as the first executive secretary-treasurer in 1947, the APS has benefited from administrative leadership provided by three additional physiologists: Ray G. Daggs (1956-1972), Orr E. Reynolds (1973-1985), and Martin Frank (1985-present).

${ }^{1}$ History of The American Physiological Society. The First Century, 1887-1987, ed. Brobeck JR, Reynolds OE, Appel TA. The American Physiological Society, Bethesda, MD. 1987. 
M. Frank

Although working in an association to advance the discipline and to serve a community is fun, you can move into the business or academic world on the basis of your management expertise. Science policy staff can move to a university to serve as government relations staff interacting with elected representatives to seek support for the institution. Similarly, with the development of university outreach programs in education and communications, opportunities exist for individuals who have developed this expertise at scientific societies. In all three areas (science policy, education, and communications), similar jobs are available in the pharmaceutical industry as well as with other business entities.

For those working in the editorial or acquisition areas of publications, positions exist within the commercial publishing houses that are responsible for the vast majority of our scientific journals and monographs. Similarly, many academic institutions have academic presses that recruit individuals with $\mathrm{PhD}$ degrees for positions similar to those in the publications operations of a scientific society.

Individuals in executive positions can move to larger associations or into executive/admin- istrative positions in academia or industry. $\mathrm{Al}-$ ternatively, one can remain with an association until retirement, as I expect to do, and then become a consultant to other associations or the development officer who solicits donations for the organization.

\section{WWW RESOURCES}

http://www.aaas.org/programs/education/ MassMedia Mass media science and engineering fellows program, American Association for the Advancement of Science (AAAS).

http://www.asaecenter.org American Society of Association Executives (ASAE).

http://www.asbmb.org/asbmbtoday ASBMB Today, a monthly publication distributed to members of the American Society for Biochemistry and Molecular Biology.

http://www.CESSE.org Council of Engineering and Scientific Society Executives (CESSE).

http://www.sfn.org/index.aspx?pagename=baw_home Brain Awareness Campaign, Society for Neuroscience.

http://www.the-aps.org American Physiological Society.

http://www.the-aps.org/mm/Education/K-12/ EducationProjects/PhUn-Week Early education program, Physiology Understanding Week, American Physiological Society.

www.wgaesf.org/ Evans Scholars Foundation, Western Golf Association. 


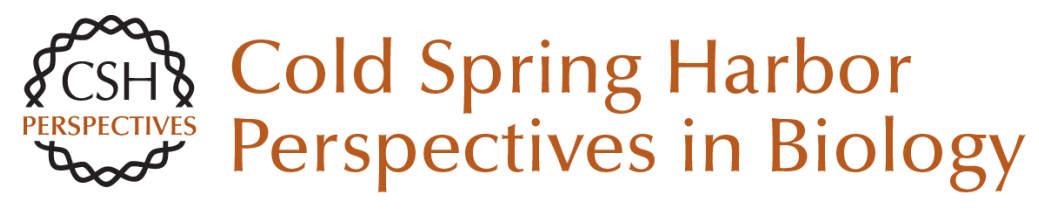

\title{
Working for a Scientific Society
}

\author{
Martin Frank
}

Cold Spring Harb Perspect Biol 2018; doi: 10.1101/cshperspect.a032888

\section{Subject Collection Career Options for Biomedical Scientists}

\section{Careers in Science Publishing} John R. Inglis

Medical Communications: The "Write" Career

Path for You? Yfke Hager

At the Crossroads of Science and Society: Careers in Science Policy Amy P. Patterson, Mary E. Groesch, Allan C. Shipp, et al.

A Career in Patent Law: At the Cutting Edge of Science, but Not at the Bench Salim Mamajiwalla

Careers in Science and Grant Administration: View from the National Institutes of Health Marion Zatz and Sherry Dupere

\section{Careers at Biotech Start-Ups and in \\ Entrepreneurship Susan Froshauer}

Careers in Science Journalism and Writing Helen Pearson

\author{
Careers in Academic Administration \\ Lydia Villa-Komaroff \\ Working for a Scientific Society \\ Martin Frank
A Career for Life Scientists in Management Consulting Rodney W. Zemmel \\ Careers in Core Facility Management \\ Claire M. Brown \\ Leaving the Bench and Finding Your Foundation \\ John E. Spiro
A Career at a Small Liberal Arts College Jennifer Punt \\ Career Options for Scientists \\ Richard Sever and Kaaren Janssen
}

For additional articles in this collection, see http://cshperspectives.cshlp.org/cgi/collection/

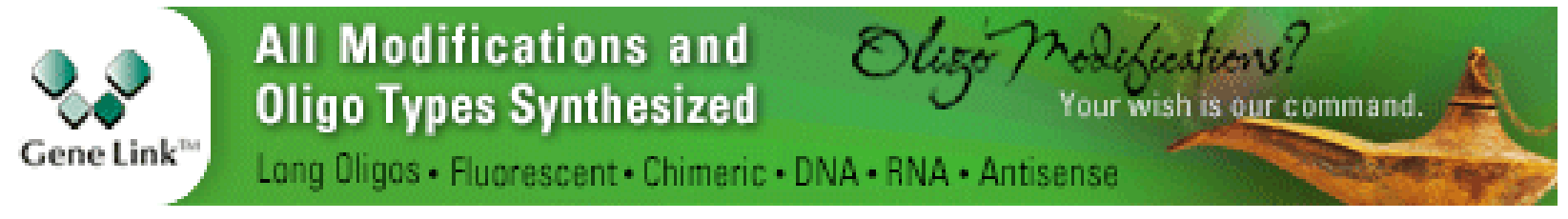

